\title{
RESÍDUOS DE INDÚSTRIA MADEIREIRA: \\ CARACTERIZAÇÃO, CONSEQUÊNCIAS SOBRE O MEIO AMBIENTE E OPÇÕES DE USO
}

\section{RESIDUE OF WOOD INDUSTRY: CHARACTERIZATION, CONSEQUENCES ABOUT ENVIRONMENT AND ALTERNATIVE USE}

\section{Nascimento, S. M. ${ }^{1}$, Dutra, R. I. J. P ${ }^{2}$; Numazawa, S. $^{3}$}

${ }^{1}$ Engenheiro Ambiental pela Universidade do Estado do Pará - UEPA, Rua Capitão Noé de Carvalho n. ${ }^{\circ} 2273$ - Santa Izabel - PA, 68970-000, tel: 91-99631133, Brasil. e-mail: engsuzi@yahoo.com.br; ${ }^{2}$ Engenheiro Ambiental pela Universidade do Estado do Pará - UEPA, trav. Barão do triunfo 1075 - Belém - PA, 66083-100, tel: 91-

2546106/91-81377602, Brasil. e-mail: engdutra@yahoo.com.br; ${ }^{3}$ Engenherio Florestal (FCAP), Professor Dr. da Universidade Federal Rural da Amazônia UFRA; Av. Presidente Tancredo Neves, 2501 - Belém - PA, 66077-530, Brasil. email: sueonuma@yahoo.com.br.

\section{RESUMO}

O estudo teve como objetivo caracterizar os resíduos de indústria madeireira, as conseqüências que os mesmos podem causar ao meio ambiente e quais as alternativas de uso. Para tal, foi realizada um levantamento de campo para quantificar o volume de resíduos, com dados coletados a partir de uma serraria localizada no município de Mojú - PA, possibilitando a análise física dos mesmos no Laboratório de Tecnologia de Produtos Florestais -LTPF - UFRA para determinação de seus usos. Verificou-se que a indústria possui uma logística rudimentar, ou seja, seu sistema de produção apresentou baixo rendimento, gerando grande quantidade de resíduos, sugerindo que os mesmos fossem utilizados para confecção de artefatos.

Palavras-chave: resíduo de madeira, impacto ambiental, combustão e pirólise.

ABSTRACT
The objective of this study was to characterize waste residues from the lumber 
industry, their consequences for the environment, and possible alternative uses. A field survey was carried out to quantify the volume of residues, with data collected from a sawmill located in the city of Mojú-Pará. Physical analyses of these residues were conducted in the Laboratory of Technology of Forest Products - LTPF - UFRA to determine their uses. Findings indicated that the industry employs rudimentary logistics; in other words, the production system resulted in low yields and generated a great amount of residues of wood that could be used to fabricate workmanship.

Key words: wood residue, environmental impact, combustion and pirolise.

\section{INTRODUÇÃO}

Nos últimos 20 anos, a Amazônia Oriental tornou-se a principal região produtora de madeira do Brasil (VERÍSSIMO et al., 1992). Muito deste crescimento ocorreu no Estado do Pará, principalmente na parte oriental, próximo ao município de Paragominas. O número de fábricas de laminados e serrarias saltou de duas, com uma produção total de madeira de $8.600 \mathrm{~m}^{3} \mathrm{em} \mathrm{1970,} \mathrm{para} \mathrm{duzentos} \mathrm{e} \mathrm{trinta} \mathrm{e} \mathrm{oito,} \mathrm{com}$ uma produção de mais de 1,2 milhão de $\mathrm{m}^{3}$ em 1990 (VERÍSSIMO et al., 1992). Atualmente, a maioria desta produção esta sendo absorvida pela demanda nacional de madeira.

As indústrias madeireiras geram grande quantidade de resíduos, apresentando um baixo rendimento, e se os mesmos forem dispersos ao meio ambiente podem trazer sérios problemas de poluição, especialmente, em sua incineração sem um prévio controle ambiental.

Segundo Fontes (1994) encontramos a carbonização e a combustão da madeira, como uma das alternativas de redução dos resíduos de indústrias madeireiras, só que tal o processo, apesar de reduzi-los, geram impactos ao meio ambiente através da liberação de gases e derivados, com isso, a utilização desses resíduos em artefatos torna-se a solução menos impactante ao meio.

Dessa forma o presente trabalho consistiu em caracterizar os resíduos de madeira, estimar as quantidades de emissões de efluentes gerados durante os processos de combustão e carbonização (pirólise), e a redução destas emissões ao transformar o resíduo em artefatos. Para embasar o estudo sobre a caracterização dos resíduos de indústrias madeireiras, a coleta de dados deu-se em uma indústria madeireira, localizada na PA-150, Km 01, Município de Mojú-PA, pertencente a Mesorregião do Nordeste Paraense e à Microrregião de Tomé-Açu. A sede municipal apresenta as seguintes coordenadas geográficas: $01^{\circ} 53^{\prime} 10^{\prime \prime} \mathrm{S} 48^{\circ} 46^{\prime} 00^{\prime \prime} \mathrm{W}$ Gr, distante a $61 \mathrm{Km}$ da capital Belém em linha reta. No empreendimento pesquisado constatou-se que os maquinários responsáveis pela produção de madeira serrada diariamente são: uma serra fita, duas destopadeiras e dois balancins. 


\subsection{Caracterização dos Resíduos de Madeira}

\section{- Classificação dos resíduos.}

Resíduo: é tudo aquilo que sobra de um processo de produção industrial ou exploração florestal (FONTES, 1994).

Segundo Fontes (1994) o extinto IBDF (1998), (Instituto Brasileiro de Desenvolvimento Florestal) e a Universidade Federal do Paraná classificaram os resíduos em três tipos distintos, ou seja:

a) serragem - resíduo originado da operação de serras, encontrado em todos os tipos de indústria, à exceção das laminadoras.

b) cepilho - conhecido também por maravalha, resíduo gerado pelas plainas nas instalações de serraria/beneficiamento e beneficiadora (indústrias que adquirem a madeira já transformada e a processam em componentes para móveis, esquadrias, pisos, forros, etc.).

c) lenha - resíduo de maiores dimensões, gerado em todos os tipos de indústria, composto por costaneiras, aparas, refilos, resíduos de topo de tora, restos de lâminas.

\section{- Caracterização Física da Madeira (Densidade e Poder Calorífico) \\ Densidade}

Os resíduos ligno-celulósicos geralmente apresentam baixa densidade, elevado teor de umidade e são dispersos geograficamente, encarecendo a coleta e o transporte, dificultando seu aproveitamento energético. Apresentam uma grande diversidade de formas e granulometria variada. Portanto, uma característica bastante comum dos resíduos é a heterogeneidade. No caso específico de resíduos de madeira há uma variação muito grande da densidade que pode variar de 0,16 a $1,3 \mathrm{~g} / \mathrm{cm}^{3}$. Para madeiras consideradas leves podem-se encontrar densidades entre 0,49 a $0,55 \mathrm{~g} / \mathrm{cm}^{3}$; para madeiras moderadamente pesadas tem-se valores de 0,63 a $0,71 \mathrm{~g} / \mathrm{cm}^{3}$ e para madeiras pesadas encontram-se densidades de 0,76 a $0,82 \mathrm{~g} / \mathrm{cm}^{3}$ (SUPERINTENDÊNCIA DO DESENVOLVIMENTO DA AMAZÔNIA, 1983). As madeiras incluídas no Trabalho da SUDAM, (1983) para a determinação do peso específico (densidade básica da madeira), forma realizadas em condições em que os corpos de prova foram imersos em água para posterior execução dos ensaios.

\section{Poder calorífico}

O poder calorífico da madeira (resíduos) consiste na quantidade de calorias liberadas na combustão completa de uma unidade de massa do combustível. A unidade mais usada no Brasil para combustíveis sólidos é a $\mathrm{kcal} / \mathrm{kg}$ ou cal $/ \mathrm{g}$. para combustíveis gasosos é cal $/ \mathrm{m}^{3}$. Sua determinação pode ser teórica pelo conhecimento da composição química do combustível ou experimental com o auxílio da bomba calorimétrica.

O poder calorífico superior (PCS) é aquele obtido na bomba calorimétrica a partir do combustível seco. O poder calorífico inferior (PCI) é aquele calculado a partir do PCS considerando o teor de umidade a que se encontra o combustível. 
O poder calorífico inferior retrata melhor a qualidade do combustível. O calor de vaporização da água é de $580 \mathrm{kcal} / \mathrm{kg}$. A diferença entre PCI e PCS está na quantidade de água presente na madeira, ou seja, no calor necessário para vaporizar esta água $(580 \mathrm{kcal} / \mathrm{kg})$ e também devido à fração de água do combustível não aproveitada na combustão.

Tabela 1 - Poder calorífico líquido da madeira em diferentes teores de umidade.

\begin{tabular}{|c|c|}
\hline Teor de umidade (\%) & Kcal/Kg \\
\hline 0 & 4000 \\
\hline 10 & 3540 \\
\hline 20 & 3080 \\
\hline 30 & 2620 \\
\hline 40 & 2160 \\
\hline
\end{tabular}

Fonte: Brito, 1993.

O poder calorífico superior da madeira seca (teor de umidade $0 \%$ ) está em torno de $4000 \mathrm{kcal} / \mathrm{kg}$ (Tabela 1). O aspecto que diminui mais a eficiência da madeira como combustível é o teor de umidade que pode atingir até $100 \%$ do peso da madeira úmida.

\section{- Combustão e Pirólise}

A madeira apresenta em sua composição química as seguintes percentagens de substâncias: carbono (C) 50\%, Hidrogênio (H) 6\% e oxigênio (O) $44 \%$, que no processo de combustão libera $\mathrm{CO}_{2}$ e $\mathrm{H}_{2} \mathrm{O}$ (GUIDE, 1985), conforme mostra figura1, abaixo:

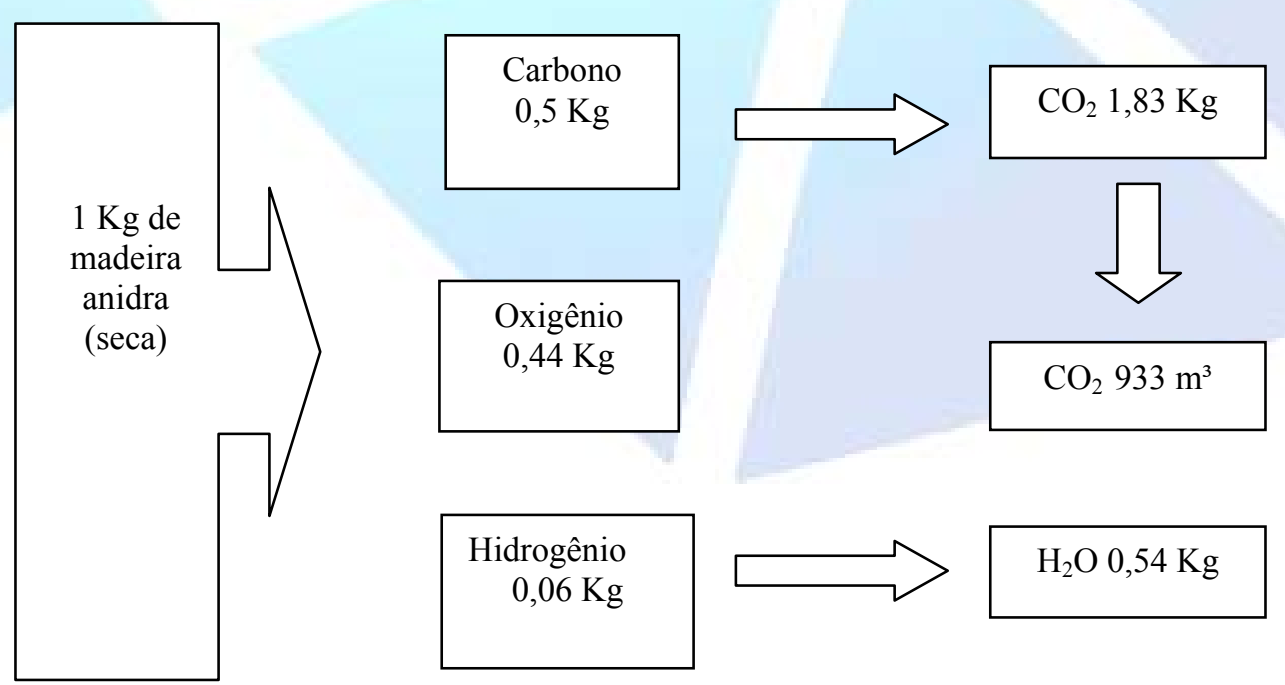

Fonte: Guide Technique de la Carbonisation la Fabrication du Charbon de Bois

Figura 1. Produtos obtidos a partir de $1 \mathrm{Kg}$ de madeira anidra. 
Já no processo de carbonização da madeira, há uma porcentagem maior de elementos gerados (Figura 2). Pois para o processo de carbonização da madeira, o carvão é apenas uma fração dos produtos que podem ser obtidos.

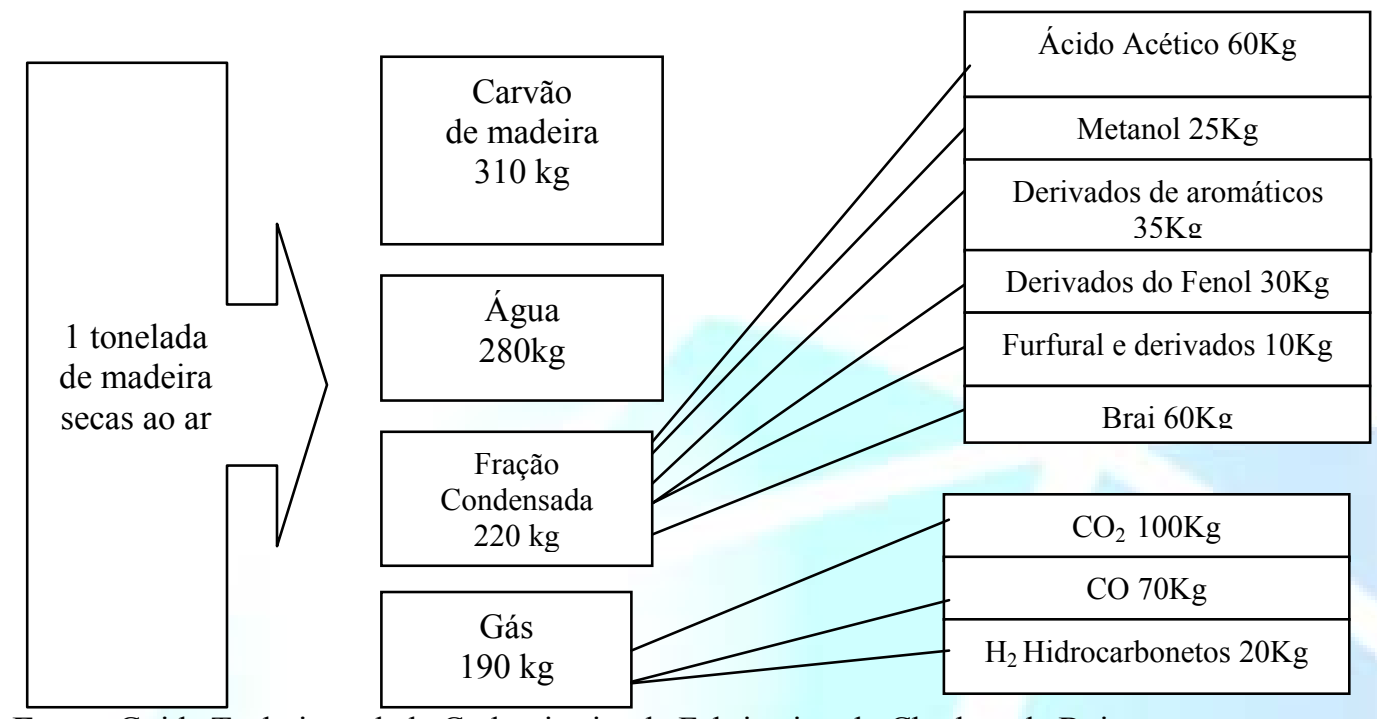

Fonte: Guide Technique de la Carbonisation la Fabrication du Charbon de Bois

Figura 2. Produtos obtidos a partir de 1 tonelada de madeira seca ao ar

\section{- Impacto Ambiental}

Atualmente $52,8 \%$ dos resíduos gerados no país são gerenciados de forma inadequada (BORGES, 1993), incluindo nesta percentagem os resíduos industriais (madeireiras etc.), muitas empresas não aproveitam de maneira coerente os seus resíduos alegando que a relação custo/benefício não justifica. Em função da destinação inadequada de seus resíduos, ocasionando desconforto, além de diversas conseqüências negativas, tanto social (prejudiciais a saúde), como ambiental (impacto ao meio ambiente devido ao acúmulo de resíduo), se enquadrando na constituição como fonte poluidora. Os impactos causados por esses resíduos provenientes de serrarias ao meio ambiente estão diretamente ligados à exploração madeireira e na quantidade de serragem desperdiçada ou queimada.

\section{OBJETIVOS}

\section{Geral:}

O trabalho teve a finalidade de quantificar e caracterizar os resíduos de madeira de uma serraria, bem como avaliar as conseqüências de seu uso sob os aspectos ambientais.

\section{Específicos:}

$\checkmark$ Quantificar os resíduos de madeira para determinação de aptidões de uso; 
$\checkmark$ Caracterização física (densidade e poder calorífico da madeira);

$\checkmark$ Estimar as emissões de gases e vapores na atmosfera devido a tradicional queima direta e carbonização de resíduos, como também o nível de redução dos mesmos ao se transformar em artefatos.

\section{METODOLOGIA}

A metodologia proposta do trabalho foi realizada em duas fases: na primeira realizou-se um trabalho de campo para quantificação de resíduos gerados na indústria; a segunda consistiu em análises laboratoriais referentes a caracterizações físicas dos mesmos, levando em consideração a estimativa de quantidade de gases e vapores lançados na atmosfera devido à combustão direta e carbonização.

\subsection{Espécies Estudadas}

As espécies estudadas foram, Muiracatiará (Astronium lecointei, Ducke), Maçaranduba (Manilkara huberi, (Ducke), Chevalier), e Guajará (Pouteria sp), identificadas através de caracteres anatômicos da madeira, no Laboratório de Tecnologia de Produtos Florestais - LTPF (1998), da Universidade Federal Rural da Amazônia - UFRA, utilizando-se a metodologia do IBDF - Madeiras da Amazônia.

\subsection{Quantificação de Resíduos na Indústria}

Esta fase foi realizada na indústria madeireira da cidade de Mojú-PA, para determinar a quantidade de resíduos, passando por três etapas abaixo descritas:

\section{Etapa I: Determinação de Volume Geométrico da Tora}

$\mathrm{O}$ volume geométrico das toras foi determinado, tomando-se o diâmetro médio das extremidades da tora (Figura 3) e o comprimento da mesma (Figura 4). Foram utilizadas três toras por espécie, as quais serviram de repetição para estudo de rendimento do processamento primário da madeira.

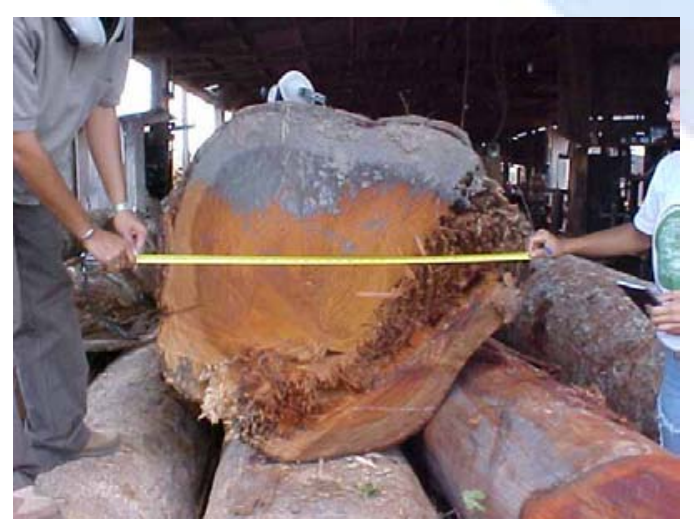

Figura 3- Determinação do diâmetro médio da tora

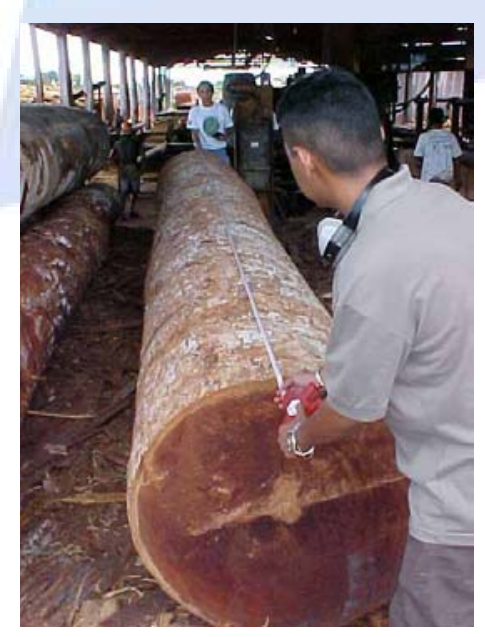

Figura 4- Determinação do comprimento da tora 


\section{Etapa II: Determinação de Resíduos Produzidos na Serra Fita (processamento primário)}

$\mathrm{O}$ volume de resíduos foi determinado com base na diferença entre o volume da tora e o volume de serrados obtidos no processamento mecânico, utilizando a equação 1:

$$
\mathrm{VR}_{(\text {Etapa } 1)}=\mathrm{VT}-\mathrm{VS}_{(\text {Etapa } 1)}
$$

Equação 1

Onde: $\quad$ VR - volume de resíduos, $\mathrm{m}^{3}$.

VT - volume da tora, $\mathrm{m}^{3}$.

VS - volume de serrados, $\mathrm{m}^{3}$.

Para a determinação do volume de serrados, fez-se a cubagem de cada peça, conforme mostrada na figura 5: (a) Medição da espessura, (b) largura e (c) comprimento da peça.
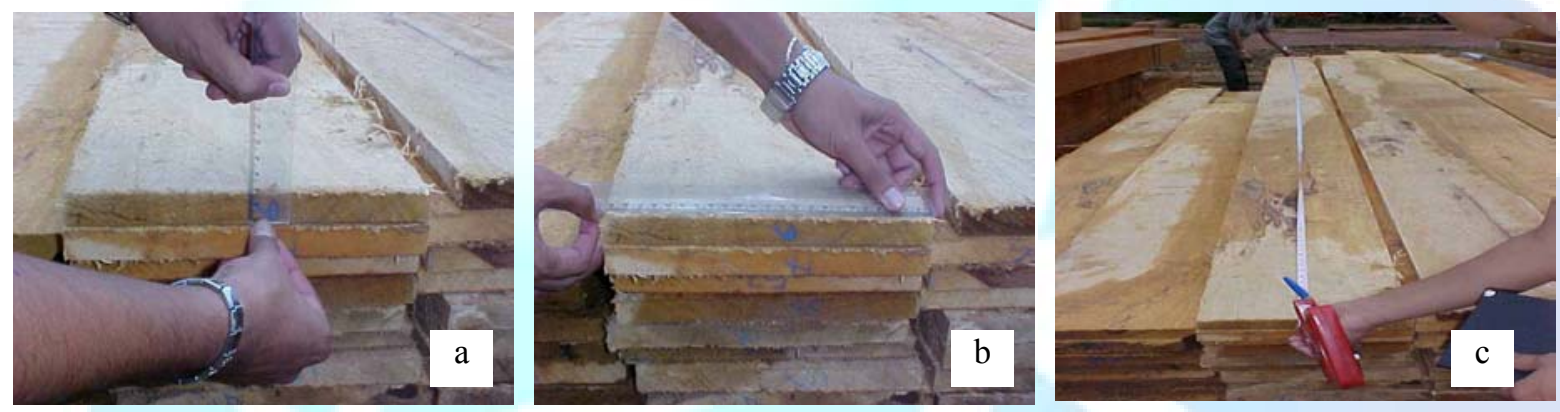

Figura 5- Cubagem dos serrados produzidos

\section{Etapa III: Classificação dos Resíduos}

A partir do volume total de resíduos calculados através da Equação 1, quantificou-se a serragem, aparas e costaneiras com base nos percentuais indicados por Carré e Schenkel (1992) de 10\% em serragem, por Contente et al. (2002) de $21,54 \%$ em costaneiras e Numazawa (2003) de 21,03\% em aparas de grosso calibre para produção de artefatos e o restante é empregado na produção de energia.

\subsection{Caracterizações Físicas dos Resíduos}

Nesta etapa, foram estudadas duas propriedades importantes na questão de uso da madeira para artefatos e energia: a densidade e o poder calorífico. As amostras foram coletadas na serraria e levadas para o Laboratório de Tecnologia de Produtos Florestais - LTPF da UFRA onde foram realizados os estudos.

\section{Determinação da Densidade da Madeira}

A densidade básica da madeira foi determinada com base na Norma MB 
1269/79 da ABNT (Associação Nacional de Normas Técnicas, 1979), através da equação 2.

$$
\rho_{(\text {básica })}=\frac{m}{V v}
$$

Equação 2

Onde: $\quad \rho$ (básica) - densidade básica da madeira, $\mathrm{g} / \mathrm{cm}^{3}$;

$\mathrm{m} \quad$ - massa do corpo de prova absolutamente seco, g;

$\mathrm{Vv}$ - volume do corpo de prova saturado ou volume verde, $\mathrm{cm}^{3}$.

A determinação da densidade básica da madeira foi realizada de acordo com as pesagens das amostras secas em estufa, e para a determinação do volume utilizou-se o princípio de Arquimedes.

\section{Determinação do Poder Calorífico da Madeira}

O poder calorífico do carvão foi determinado segundo a Norma D 250/50 da ASTM (AMERICAN SOCIETY FOR TESTING AND MATERIAL, 1978), em uma bomba calorimétrica adiabática baseada no método de Berttelot, que consiste na combustão do material em um ambiente fechado na presença de oxigênio e sob pressão.

\subsection{Estudo Teórico para Estimar a Quantidade Emissões de Gases e Vapores} Formados na Decomposição Térmica da Madeira.

$\checkmark$ Incineração de resíduos (combustão).

A quantidade de emissão de $\mathrm{CO}_{2}$ e produção de $\mathrm{H}_{2} \mathrm{O}$, devido à combustão dos resíduos, foi calculada com base nas reações abaixo, para $1 \mathrm{Kg}$ de madeira anidra:

$$
\begin{aligned}
\mathrm{C}+\mathrm{O}_{2} \Rightarrow \mathrm{CO}_{2}+\text { calor } \\
2 \mathrm{H}_{2}+\mathrm{O}_{2} \Rightarrow 2 \mathrm{H}_{2} \mathrm{O}+\text { Calor }
\end{aligned}
$$

$\mathrm{O}$ cálculo para estimar a quantidade de $\mathrm{CO}_{2}$ emitida e a produção de $\mathrm{H}_{2} \mathrm{O}$, gerados durante a combustão foi determinado de acordo com Guide Technique de la Carbonisation la Fabrication du Charbon de Bois, citado na Figura 1.

\section{$\checkmark$ Produção de Carvão (pirólise)}

O cálculo para estimar as emissões geradas durante o processo da pirólise, foi determinado de acordo com Guide Technique de la Carbonisation la Fabrication du Charbon de Bois, para 1 tonelada de madeira seca, citado na Figura 2. 


\section{RESULTADOS E DISCUSSÃO}

\subsection{Quantificação de Resíduos na Serraria}

$\mathrm{Na}$ Tabela 2, encontram-se os rendimentos de serrados e resíduos gerados no processamento primário da tora. As espécies Muiracatiará (Astronium lecointei, Ducke) e Guajará (Pouteria $s p$ ) foram as que apresentaram menores rendimentos de serrados, conseqüentemente, maior quantidade de resíduos. A espécie Maçaranduba (Manilkara huberi, (Ducke) Chevalier) apresentou um rendimento de serrado bem próximo da média de 50\% encontrada pela SUDAM - Superintendência do Desenvolvimento da Amazônia, (1981) ao se fazer um estudo com trinta e duas espécies da Amazônia.

Tabela 2-Volume total de madeira, serrado e resíduo.

\begin{tabular}{|c|c|c|c|c|c|}
\hline \multirow{2}{*}{ Espécie } & \multicolumn{3}{|c|}{ Volume $\left(\mathrm{m}^{3}\right)$} & \multirow{2}{*}{$\begin{array}{c}(\%) \\
\text { Rendimento } \\
\text { serrado }\end{array}$} & \multirow{2}{*}{ (\%) Resíduo } \\
\hline & Tora & Serrado & Resíduo & & \\
\hline Muiracatiará & 7,24 & 2,34 & 4,90 & 32,3 & 67,68 \\
\hline Maçaranduba & 8,11 & 3,34 & 4,77 & 41,2 & 58,82 \\
\hline Guajará & 5,94 & 2,09 & 3,85 & 35,2 & 64,81 \\
\hline TOTAL & 21,29 & 7,77 & 13,52 & 36,50 & 63,50 \\
\hline
\end{tabular}

Tabela 3 - Repartição de resíduos gerados na serraria

\begin{tabular}{|l|c|c|c|c|c|c|}
\hline \multirow{2}{*}{ Espécies } & \multicolumn{2}{|c|}{ Costaneiras } & \multicolumn{2}{|c|}{ Aparas } & \multicolumn{2}{c|}{ Serragem } \\
\cline { 2 - 7 } & $\left.\mathbf{( m}^{\mathbf{3}}\right)$ & $\%$ & $\left.\mathbf{( m}^{\mathbf{3}}\right)$ & $\%$ & $\left.\mathbf{( m}^{\mathbf{3}}\right)$ & $\%$ \\
\hline Muiracatiará & 1,56 & 31,8 & 2,62 & 53,4 & 0,72 & 14,8 \\
\hline Maçaranduba & 1,75 & 36,6 & 2,21 & 46,4 & 0,81 & 17,0 \\
\hline Guajará & 1,28 & 33,2 & 1,98 & 51,3 & 0,59 & 15,4 \\
\hline Total & $\mathbf{4 , 5 9}$ & $\mathbf{3 3 , 9}$ & $\mathbf{6 , 8 1}$ & $\mathbf{5 0 , 4}$ & $\mathbf{2 , 1 3}$ & $\mathbf{1 5 , 7}$ \\
\hline
\end{tabular}


$\mathrm{Na}$ Tabela 3, encontra-se a repartição dos resíduos de acordo com a sua classificação. Constatou-se que o maior percentual de resíduos formados se constituiu de aparas com 50,4\%, seguidos por costaneiras com 33,9\% e serragem com $15,7 \%$.

Da média de 50,4\% de aparas (Figura 6) das três espécies estudadas, pode-se destinar 21,03\%, conforme sugere Numazawa (2003), para fabricação de artefatos correspondendo a $1,43 \mathrm{~m}^{3}$ e o restante de $5,38 \mathrm{~m}^{3}$ para energia juntamente com a serragem.

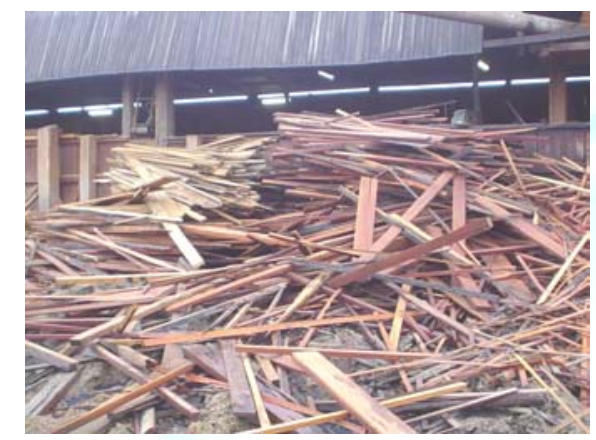

Figura 6 - Aparas

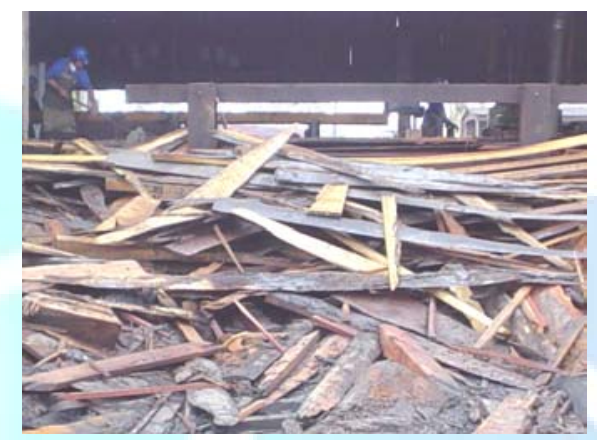

Figura 7- Costaneiras

No que concerne as costaneiras, sugere-se a sua destinação para fabricação de carvão vegetal, pois apresentam formas irregulares (espessura e largura não contínua), de acordo como mostra a figura 7.

\subsection{Densidade da Madeira}

Com base nas análises em laboratório, encontraram-se os valores de densidade básica da madeira das espécies estudadas. Muiracatiará $\left(0,71 \mathrm{~g} / \mathrm{cm}^{3}\right)$ e Maçaranduba $\left(0,72 \mathrm{~g} / \mathrm{cm}^{3}\right)$ são madeiras pesadas e Guajará $\left(0,54 \mathrm{~g} / \mathrm{cm}^{3}\right)$ leve, conforme a classificação da Superintendência do Desenvolvimento da Amazônia (1983).

\subsection{Determinação do Poder Calorífico}

Os valores de poder calorífico superior encontrados foram: Muiracatiará 4022 $\mathrm{Kcal} / \mathrm{Kg}$, Maçaranduba $4248 \mathrm{Kcal} / \mathrm{Kg}$ e Guajará $4263 \mathrm{Kcal} / \mathrm{Kg}$, que confirmam os dados encontrados em literaturas. Brito (1993), encontrou valor médio $4000 \mathrm{Kcal} / \mathrm{Kg}$ para o poder calorífico líquido da madeira, podendo também encontrar resultados acima deste valor chegando até a $4800 \mathrm{kcal} / \mathrm{kg}$.

\subsection{Emissões de Gases e Vapores de Combustão e Pirólise de Resíduos de Madeira}

$\mathrm{Na}$ tabela 4, encontram-se os valores de massa dos resíduos e as suas respectivas emissões efluentes da combustão. Verificou-se que a espécie Muiracatiará foi a que apresentou a maior massa e o maior grau de emissões, seguida de 
Maçaranduba e Guajará. Essas espécies ao serem incineradas podem gerar, respectivamente, $5.196 .424 \mathrm{Kcal}, 4.035 .600 \mathrm{Kcal}$ e $3.039 .519 \mathrm{Kcal}$, total de 12.271.543 Kcal, equivalente a 1.115 TEP (tonelada equivalente petróleo).

Tabela 4 - Massa de resíduo destinado à combustão

\begin{tabular}{|c|c|c|c|c|c|c|}
\hline Espécie & $\begin{array}{c}\text { Volume de } \\
\text { resíduos }\left(\mathbf{m}^{3}\right)\end{array}$ & $\begin{array}{c}\text { Densidade } \\
\left(\mathrm{g} / \mathrm{cm}^{3}\right)\end{array}$ & $\begin{array}{c}\text { Massa } \\
\text { (kg) }\end{array}$ & $\begin{array}{l}\mathrm{CO}_{2} \\
(\mathrm{Kg})\end{array}$ & $\begin{array}{c}\text { Volume } \\
\text { de } \mathrm{CO}_{2} \\
\left(\mathrm{~m}^{3}\right)\end{array}$ & $\begin{array}{l}\mathrm{H}_{2} \mathrm{O} \\
(\mathrm{Kg})\end{array}$ \\
\hline Muiracatiará & 1,82 & 0,71 & 1292 & 2.369 & 1.206 & 698 \\
\hline Maçaranduba & 1,32 & 0,72 & 950 & 1.742 & 887 & 513 \\
\hline Guajará & 1,32 & 0,54 & 713 & 1.307 & 665 & 385 \\
\hline
\end{tabular}

Em geral, nas indústrias madeireiras tradicionais, os resíduos são incinerados a céu aberto, lançando todos os efluentes na atmosfera. Com base no volume total de resíduos gerados e na média da densidade das espécies estudadas, estimou-se uma produção de efluentes de $8.328 \mathrm{~m}^{3}$ de $\mathrm{CO}_{2}$ e $4.818 \mathrm{Kg}$ de água.

Com base na massa de resíduos de costaneiras de cada espécie e no percentual de conversão pirolítica da madeira em carvão vegetal (Tabela 4), estimou-se a quantidade das frações sólida, líquida e gasosa. Constatou-se que espécie Maçaranduba possui o maior potencial para produção de carvão, seguida de Muiracatiará e Guajará. Um carvão produzido com resíduos de indústrias madeireiras, segundo Aquino (2002), pode liberar cerca de $7.177 \mathrm{Kcal}$ de energia por quilo de carvão. Considerando esse potencial energético, pode-se gerar, respectivamente, $2.461 .711 \mathrm{Kcal}, 2.806 .207 \mathrm{Kcal}$ e $1.535 .878 \mathrm{Kcal}$, total de 6.803.796 Kcal de energia através de combustão direta do carvão, equivalendo a 618.5 TEP.

Tabela 5 - Massa de resíduo destinado à carbonização.

\begin{tabular}{|l|l|l|l|l|l|l|l|}
\hline Espécie & $\begin{array}{l}\text { Volume de } \\
\left.\text { resíduos } \mathbf{( m}^{\mathbf{3}}\right)\end{array}$ & $\begin{array}{l}\text { Densidade } \\
\left(\mathbf{g} / \mathbf{c m}^{\mathbf{3}}\right)\end{array}$ & $\begin{array}{l}\text { Massa } \\
(\mathbf{k g})\end{array}$ & $\begin{array}{l}\text { Carvão } \\
\mathbf{( K g )}\end{array}$ & $\begin{array}{l}\text { Água } \\
(\mathbf{K g})\end{array}$ & $\begin{array}{l}\text { Vapor } \\
(\mathbf{K g})\end{array}$ & $\begin{array}{l}\text { Gases } \\
(\mathbf{K g})\end{array}$ \\
\hline Muiracatiará & 1,56 & 0,71 & 1108 & 343 & 310 & 244 & 210 \\
\hline Maçaranduba & 1,75 & 0,72 & 1260 & 391 & 353 & 277 & 239 \\
\hline Guajará & 1,28 & 0,54 & 691 & 214 & 194 & 152 & 131 \\
\hline
\end{tabular}

No que concerne à emissão de gases e vapores, verificou-se que a conversão pirolítica foi mais agressiva do que a simples combustão. Nesse processo, além de $\mathrm{CO}_{2}$ e vapor d'água, ainda é formado o licor pirolenhoso, constituído por inúmeras substâncias fenólicas, diversos ácidos e outras substâncias que causam impacto ambiental (chuva ácida, efeito estufa, etc.). 
Tabela 6 - Valores dos componentes gerados a partir de vapores e gases da produção da Indústria

\begin{tabular}{|c|c|c|c|c|c|c|c|c|c|}
\hline \multirow[b]{2}{*}{ Espécies } & \multicolumn{6}{|c|}{ Vapores } & \multicolumn{3}{|r|}{ Gases } \\
\hline & $\begin{array}{c}\text { Ac. } \\
\text { Acético } \\
(\mathbf{K g})\end{array}$ & $\begin{array}{c}\text { Metanol } \\
(\mathrm{Kg})\end{array}$ & $\begin{array}{c}\text { Derivados } \\
\text { de Fenol } \\
\text { (Kg) }\end{array}$ & $\begin{array}{c}\text { Derivados e } \\
\text { Aromáticos } \\
\quad(\mathrm{Kg})\end{array}$ & $\begin{array}{l}\text { Brai } \\
(\mathbf{K g})\end{array}$ & $\begin{array}{l}\text { furfural e } \\
\text { derivados } \\
\text { (Kg) }\end{array}$ & $\begin{array}{l}\mathrm{CO}_{2} \\
(\mathrm{Kg})\end{array}$ & $\begin{array}{c}\mathrm{CO} \\
(\mathrm{Kg})\end{array}$ & $\begin{array}{c}\mathrm{H}_{2}-\text { Hidrocarbonetos } \\
\text { (Kg) }\end{array}$ \\
\hline Muiracatiará & 67 & 28 & 33 & 39 & 67 & 11 & 111 & 77 & 22 \\
\hline Maçaranduba & 76 & 31 & 38 & 44 & 76 & 12 & 126 & 88 & 25 \\
\hline Guajará & 42 & 17 & 21 & 24 & 42 & 7 & 69 & 48 & 14 \\
\hline
\end{tabular}

\section{CONCLUSÕES}

1. A serraria estudada apresentou rendimento inferior à média das serrarias tradicionais, decorrente de seu baixo nível tecnológico de conversão mecânica da tora em serrados.

2. O maior grau de perdas ocorreu no momento do corte em galgadeira e balancim que corresponde ao bitolamento das peças de serrado.

3. A combustão de resíduos (serragem e aparas de pequeno calibre) constitui uma alternativa como fonte de geração de energia térmica para secagem da madeira.

4. O uso de resíduos para produção de artefatos (aparas de grosso calibre) constitui uma alternativa para reduzir o grau de efluentes tradicionalmente lançados na atmosfera através de combustão ou fabricação de carvão vegetal.

5. O aproveitamento de resíduos pode gerar receitas através de agregação de valor aos produtos que tradicionalmente são abandonados ou queimados.

\section{REFERÊNCIAS}

ASSOCIAÇÃO BRASILEIRA DE NORMAS TÉCNICAS. ABNT. Norma MB 1269/79. Rio de Janeiro. 1979. 80p.

AQUINO, J. N., Aproveitamento de resíduos de madeira de serraria para produção de carvão e redução de área de floresta explorada. 2002. $96 f$. Dissertação (Mestrado em Manejo Florestal e Silvicultura Tropical) Instituto de Ciências Agrárias. Universidade Federal Rural da Amazônia, Belém, 2002.

AMERICAN SOCIETY FOR TESTING AND MATERIAL. ASTM. Norma D 250/50, 1978. p78-80. 
BORGES, A.S.; CINIGLIO, G.; BRITO J.O. Considerações Energéticas e Econômicas sobre Resíduos de Madeira Processada em Serraria. In: CONGRESSO FLORESTAL PAN-AMERICANO, 1.; CONGRESSO FLORESTAL BRASILEIRO, 7. 1993, Curitiba. Anais... Curitiba 1993. v.3. p 603-606.

BRITO, J. O. Expressão da produção florestal em unidades energéticas. In: CONGRESSO FLORESTAL PAN-AMERICANO, 1.; CONGRESSO FLORESTAL BRASILEIRO, 7. 1993, Curitiba. Anais.... Curitiba. v3. p 280-282.

CARRÉ, J.; SCHENKE, Y. Biomass Characteristics and combustion process in E.C. workshop: Designs and selection of biomass boilers. Yogojakarta: 1992.

CONTENTE, P. L. B; SILVA, J. N. M. Relação entre volumes de árvores em pé e volume francon. Informe Técnico da Faculdade de Ciências Agrárias do Pará. Serviço de Documentação, Belém, nº 28, p 25-41, 2002.

FONTES, P. J. P. Auto-suficiência energética em serraria de Pinus e aproveitamento dos resíduos. 1994. 90f. Dissertação (Mestrado em Engenharia Florestal). Setor Ciências Agrárias Universidade Federal do Paraná, Curitiba, 1994.

GUIDE. Technique de La Carbonisation La Fabrication Du Charbon De Bois. Agence Française Pour La Maitrise de L'Energie. Association Bois de Feu. Centre Technique Forestier Tropical. Dominique Briane - abf. Jacqueline Doat - Edisud, $1985, \mathrm{p} 28$.

INSTITUTO BRASILEIRO DE DESENVOLVIMENTO FLORESTAL. IBDF. Madeiras da Amazônia, características e utilização.Estação Experimental de CuruáUna, 1998. v. 2.

NUMAZAWA, S; CARVALHO, M. S. P.; BRANDÃO, A.T.O.; ALVES. R. L. e RODRIGUES, A.F. Determinação do índice de conversão da tora em madeira serrada de oito espécies florestais processadas ma empresa Comércio Madeira Dunorte Ltda. In: CONGRESSO INTERNACIONAL DE COMPENSADO E MADEIRA TROPICAL, 5., 2003, Belém. Anais....Belém. 2003.22p.

SUPERINTENDÊNCIA DO DESENVOLVIMENTO DA AMAZÔNIA. SUDAM. Centro de Tecnologia madeireira. Rendimento em serrarias de 30 espécies de madeiras amazônicas, Belém. 1981. p 31-58.

SUPERINTENDÊNCIA DO DESENVOLVIMENTO DA AMAZÔNIA. SUDAM. Propriedades físico-mecânica e uso comuns de 30 espécies de madeiras da Amazônia. Belém. 1983. p 7-15. 
VERISSIMO, A.; BARRETO, P.; MATTOS, M.; TARIFA, R.; UHL, C. Logging impact and prospects for sustainable forest management in an old Amazonian frontier: the case of Paragominas. Ed. Forest Ecology and Management, Amsterdam, 55, no 1/4, 169-199. 1992. 